\title{
Studies on Cooperative Emergency Regulation of Over-level Floods of Cascade Reservoirs
}

\author{
Yue Hua $^{1}$, Ma Guangwen ${ }^{1}$, Yang Gengxin ${ }^{2}$ \\ ${ }^{1}$ National key lab of hydraulics and mountain river engineering, Water Conservancy and hydropower school, Sichuan University, \\ Chengdu, Sichuan, 610065; \\ ${ }^{2}$ DaDu River Hydropower Development Co., Ltd. Chengdu, Sichuan, 610000 \\ About the author: Yue Hua (1977-), female, PhD, Chengdu, Sichuan, research area: hydrology and water resources
}

\begin{abstract}
Affected by global climate change, the frequency of extreme weather events increases in China, and the suddenness, harmfulness and unpredictability of the flood disaster exceeding the designed level are more serious. As a result, emergency response problems facing cascade reservoirs are increasingly prominent, among which the dam break or consecutive break is the greatest threat to cascade reservoirs. In case of floods exceeding the designed level, cooperative emergency regulation of cascade reservoirs is an effective method to develop the comprehensive benefit of reservoirs. In this paper, the criterion of minimizing the highest water level is chosen as the objective function of the cooperative emergency regulation model in cope with floods exceeding the designed level, with the progressive optimality algorithm adopted to solve the function. Moreover, the related emergency regulation plan is conductively explored. In addition, the Pubugou Reservoir, Shenxigou Reservoir, and Zhentouba I Reservoir on the Dadu River are taken as examples to regulate and calculate the flooding process, which verifies the validity and reliability of the preceding model. According to the results, by means of cooperative emergency regulation of cascade reservoirs, each reservoir pre-discharges water in the early flood to maximize the storage capacity, thus coping with the possibly coming flood, minimizing the water level of each reservoir, and effectively ensuring flood control safety for cascade reservoirs. The research results are of great theoretical significance and engineering practice value for establishing the emergency regulation mechanism to cope with floods exceeding the designed level for cascade reservoirs in each river basin.
\end{abstract}

CLC number: TV321 Document code: A

\section{Research Background}

As hydropower development is continuously advanced, cascade reservoirs are gradually formed in multiple large river basins. At present, there are more than 98,000 reservoirs and dams in China ${ }^{[1]}$, ranking No. 1 in the world, with the largest number of cascade reservoirs completed or under construction. As unexpected disasters and events occur frequently, emergency response problems facing cascade reservoirs are increasingly prominent, among which the dam break or consecutive break is the biggest threat to cascade reservoirs. The losses thus caused are most serious among all failure modes.

From 1954 to 2010, a total of 3513 reservoirs and dams collapsed nationwide ${ }^{[2]}$, among which 319 are caused by the catastrophic flood taking place in August of 1963. Besides, in August of 1975, the super Typhon Nina brought severe rainstorms, resulting heavy floods in the upper reach of the Huai River. Almost 60 reservoirs and dams collapsed successively, causing catastrophic losses to the people in its lower reach and the direct economic losses up to 10 billion $^{[3]}$. For a normal sudden event, the emergency plan or human decision in terms of a single reservoir or dam may possibly eliminate the effects on cascade reservoirs in the upper and lower reaches. However, in terms of an unexpected vital event of cascade reservoirs, considering emergency response only to single reservoirs and dams is very likely to cause chain disaster reaction to cascade reservoirs. Therefore, the safety guarantee of cascade reservoirs confronted with emergent events has become hot and difficult issues with common concern in the national social and economic development, in particular, the safety problem caused by unexpected flood disasters due to floods exceeding the designed level.

A lot of water conservancy workers always paid more attention to the research on dam collapse and floods and obtained many achievements in the process of dam collapse and flood routing. However, most research focused on single reservoirs. At present, comprehensive research, analysis and evaluation on the security and stability of cascade reservoirs as a whole are still seldom. ${ }^{[4]}$ The current security evaluation standards and

*Corresponding author: E-mail: yh16688@163.com 
methods are set based on single reservoirs, without considering the correlation between single reservoirs and the overall security of cascade reservoirs ${ }^{[5]}$. The emergency response for vital sudden events (such as the flood exceeding the designed level) is almost blank. Therefore, it is urgent to study the plan for the cooperative emergency response and regulation of the over-level flood for cascade reservoirs.

In consideration of different characteristics of cascade reservoirs and single reservoirs and on the basis of the analysis on the emergency regulation criterion of floods exceeding the designed level, the related emergency regulation plan is proposed in this paper, relying on the Pubugou Reservoir, Shenxigou Reservoir, and Zhentouba I Reservoir on the Dadu River. Moreover, the criterion of minimizing the highest water level is chosen as the objective function of the cooperative emergency regulation model in cope with floods exceeding the designed level, with the progressive optimality algorithm adopted to solve the function for cascade reservoirs, thus effectively mitigating the flood control pressure of cascade reservoirs, improving the overall flood control capacity in the lower reach of the Dadu River, and securing the safety and stability of cascade reservoirs in the lower reach of the Dadu River and the safety of the lives and property of people in the surrounding reaches. The research results are of great reference value for establishing the emergency regulation mechanism to cope with floods exceeding the designed level for cascade reservoirs in each river basin in China.

\section{Emergency Regulation Criterion of Floods Exceeding the Designed Level}

Reservoir flood regulation aims for flood detention, peak shaving, and peak avoiding, thus preventing floods to the greatest extent and mitigating flood disasters ${ }^{[6]}$. Flood regulation is carried out mainly in the following situations ${ }^{[7-10]}$ : reasonable flood control regulation is conducted to prevent flood disasters; in terms of catastrophic flood disasters inevitably causing losses, flood control regulation is conducted to shorten disaster retention in the flood control area in the lower reaches, that is, the criterion of minimizing disaster duration, on the premise that the reservoir safety is secured. The following criteria are used correspondingly in the preceding two situations:

\subsection{Minimizing the Highest Water Level}

In this criterion, the optimal security of the dam (reservoir) during regulation is the objective of flood control optimization and regulation for the reservoir. That is, the flood is discharged to the hilt on the premise that the safety discharge of the flood control section in the lower reach is satisfied, thus minimizing the water level of the reservoir, reserving the maximum flood control storage, and coping with the following heavy floods possibly coming.

The criterion of minimizing the highest water level can be expressed as follows:

$$
\min \left\{\max _{t \in\left[t_{0}, t_{d}\right]}[Z(t)]\right\}
$$

where, $\mathrm{t}$ is time; $t_{d}$ and $t_{0}$ refer to the start and end time of flooding respectively; $\mathrm{Z}$ is the water level of the reservoir.

In consideration of the correspondence between the water level and reservoir storage, minimizing the highest water level can be equivalent to minimizing the maximum reservoir storage. Based on the water balance principle, formula (1) can be equivalent to the following through further deduction:

$\min \left\{\max _{t \in\left[t_{0}, t_{d}\right]}[Z(t)]\right\} \Leftrightarrow \min \int_{t_{0}}^{t_{d}}[\Delta Z(t)]^{2} d t$

In flood control optimization and regulation of cascade reservoirs, the objective function of flood control regulation for a flood control system consisting of $n$ reservoirs and $n$ flood control points based on the criterion of minimizing the highest water level can be expressed as follows:

$\min \int_{t_{0}}^{t_{d}}\left\{\Delta Z_{1}^{2}(t)+\Delta Z_{2}^{2}(t)+\cdots+\Delta Z_{n}^{2}(t)\right\} d t$

In practice, the discrete form of this objective function is usually expressed as follows:

$\min \sum_{j=1}^{M} \sum_{i=1}^{n} \Delta Z_{j, i}^{2} \Delta t$

where, $j$ is the number of periods; $j=1,2, \cdots, M$, in which $M=\frac{t_{d}-t_{0}}{\Delta t} ; t_{d}$ and $t_{0}$ refer to the start and end time of flooding respectively; $\Delta t$ is the calculating interval; $\Delta Z_{j, i}$ refers to the change range of the water level in No. $i$ reservoir during No. $j$ interval; $i$ is the serial number of a cascade reservoir $i=1,2, \cdots, n$.

\subsection{Minimizing the Disaster Duration}

In this criterion, the shortest duration of successive flood disasters in the flood control protected areas in the lower reach of the reservoir is the objective of flood control optimization and regulation for the reservoir. Actually, the flood control storage of the reservoir serves to regulate floods so that the reservoir discharge exceeds the secure discharge of the flood control section in the lower reach of the reservoir. The shorter this duration, the better, that is, minimizing the flood disaster losses in the lower reach. It is based on the premise of secured flood control safety for the dam (reservoir), without insuring the flood control safety in the lower reach.

The criterion of minimizing the disaster duration can be expressed as follows ${ }^{[11]}$ :

(1) With the interval flood: 
$\min \left\{T_{\text {灾 }}\right\}=\left\{\underset{t \in\left[t_{0}, t_{d}\right]}{t} \mid\left[q(t)>q_{\text {安 }}\right]\right\}$

(2) Without the interval flood:

$\min \left\{T_{\text {灾 }}\right\}=\left\{\underset{t \in\left[t_{0}, t_{d}\right]}{t} \mid\left[\left(q(t)+Q_{\text {区 }}(t)\right)>q_{\text {安 }}\right]\right\}_{(6)}$

where, $T_{\text {灾 }}$ is the disaster duration; $t_{0}$ and $t_{d}$ refer to the start and end time of the disaster; $q(t)$ is the discharge of the reservoir at $t ; q_{\text {安 }}$ is the allowed secure discharge of the lower reach; $Q_{区}(t)$ is the interval discharge at $t$.

In consideration of the preceding situations and the cascading model of cascade reservoirs, four combinations are listed respectively as the objective functions of regulation for the flood control system in flood control points based on the criterion of minimizing the disaster duration, then to be solved.

\section{Cooperative Emergency Regulation Model of Floods Exceeding the Designed Level}

Emergency regulation of floods exceeding the designed level aims to address flood control regulation problems under immerse pressure of flood control, in particular, how to discharge reservoir water as soon as possible, lower the reservoir water level, and reserve as much reservoir storage as possible to cope with the coming flood and mitigate the flood control pressure on the reservoir through flood control regulation. Therefore, the criterion of minimizing the highest water level is chosen as the objective function of the cooperative emergency regulation model in cope with floods exceeding the designed level ${ }^{[12-15]}$ in this paper. For details about the objective function, see formula (4) in the preceding section.

In practice, the following corresponding constraints need to be introduced to solve the objective function:

(1) Constraint on flood control storage:

$\sum_{j=1}^{M}\left(Q_{j, i}-q_{j, i}\right) \Delta t=\Delta V_{j, i}$

where, ${ }^{Q_{j, i}}$ is the average inflow of No. ${ }^{i}$ reservoir at No. $j$ interval; $q_{j, i}$ is the average outflow of No. $i$ reservoir at No. $j$ interval; $\Delta V_{j, i}$ is the storage change of No. $i$ reservoir at No. $j$ interval.

(2) Constraint on reservoir water balance:

$\frac{Q_{j, i}+Q_{j+1, i}}{2}-\frac{q_{j, i}+q_{j+1, i}}{2}=\frac{\Delta V_{j, i}}{\Delta t}$

where, $\Delta V_{j, i}$ is the storage change of No. $i$ reservoir at No. $j$ interval.
(3) Constraint on reservoir water level:

$Z_{j, i}^{\min } \leq Z_{j, i} \leq Z_{j, i}^{\max }$

where, $Z_{j, i}$ is the average water level of No. $i$ reservoir at No. $j$ interval; $Z_{j, i}^{\min }$ is the allowed lowest water level of No. $i$ reservoir at No. $j$ interval; $Z_{j, i}^{\max }$ is the allowed highest water level of No. $i$ reservoir at No. $j$ interval.

(4) Outflow constraint:

$q_{j, i}^{\min } \leq q_{j, i} \leq q_{j, i}^{\max }$

where, $q_{j, i}^{\min }$ is the allowed minimum outflow of No. $i$ reservoir at No. $j$ interval; $q_{j, i}^{\max }$ is the allowed maximum outflow of No. $i$ reservoir at No. $j$ interval.

(5) Constraint on flow balance:

$Q_{j, i+1}=Q_{j-\tau_{i}, i}+Q_{区, j, i}$

where, $\tau_{i}$ is the flowing time of floods from No. $i$ reservoir to No. $i+1$ reservoir; $Q_{区, j, i}$ is the discharge from No. $i$ reservoir to No. $i+1$ reservoir at No. $j$ interval.

(6) Non-negative constraint:

All preceding variables are non-negative (all variables $\geq 0$ ).

\section{Solution Algorithm of the Cooperative Emergency Regulation Model}

There are many solution algorithms for the reservoir regulation model, among which classical mathematical methods include linear programming, non-linear programming, and dynamic programming. Each algorithm has its own advantages and disadvantages. Some of them may have the global optimal solution but take a long time. Meanwhile, some may take a short time but have the local optimal solution. The optimal solution to the reservoir optimization and regulation is to find the global optimal solution in a short time. However, in the case of complex optimization and regulation problems, it is very difficult to find a global optimal solution with a high convergence rate ${ }^{[16]}$. A large number of studies from scholars at home and abroad show that the dynamic programming algorithm is an effective method to solve single reservoir optimization and regulation. However, it will inevitably face the curse of dimensionality when being used to solve the cooperative regulation model for cascade reservoirs. At present, the most commonly used deterministic optimization method to solve the preceding model is the progressive optimality algorithm. When the 
stage index function of the multistage decision problem shows the strict convexity and first-order continuous partial derivatives, the progressive optimality algorithm can converge to the global optimal solution. In addition, owing to its invisible parallel search, this algorithm consumes a short time and therefore is highly efficient. In no need of the discrete state variable, it can not only provide a more precise solution but also overcome the curse of dimensionality faced by the dynamic programming algorithm when being used to solve the optimization and regulation problems of cascade reservoirs. Therefore, in this paper the progressive optimality algorithm is adopted to solve the cooperative emergency regulation model for cascade reservoirs in cope with floods exceeding the designed level ${ }^{[17]}$. Figure 1 shows the flow chart of solving the optimization and regulation problems of hydropower stations by using the progressive optimality algorithm.

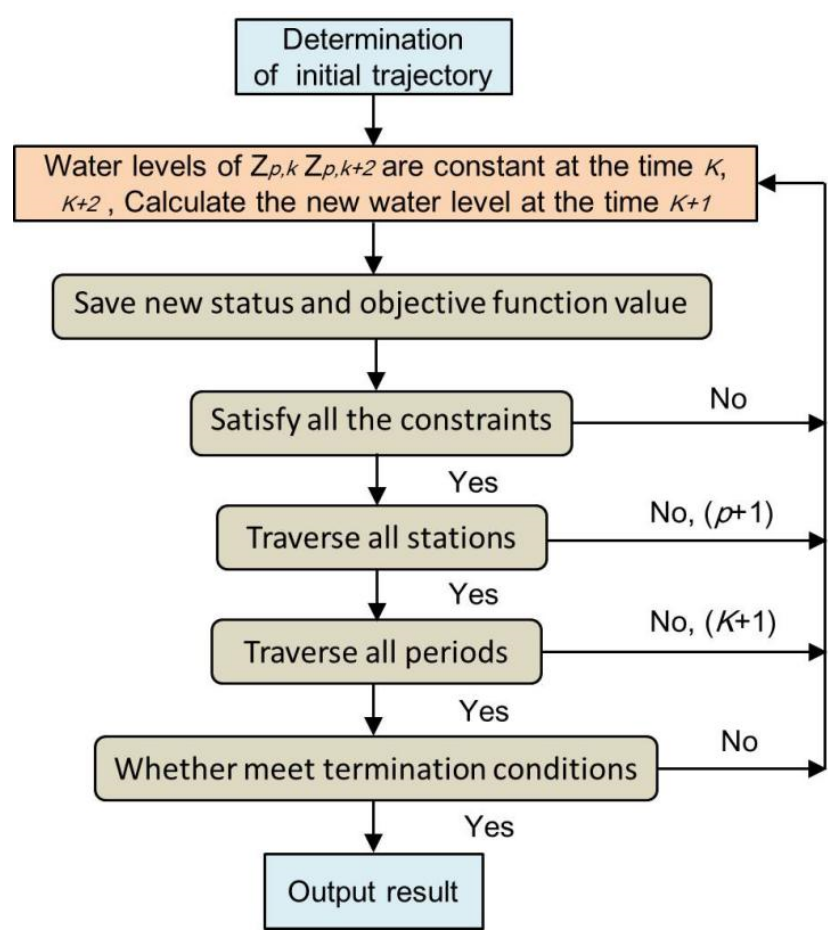

Figure 1 Flow chart of solving the optimization and regulation problems of hydropower stations by using the progressive optimality algorithm

The regulation time is divided into $T$ periods; the total number of cascade stations is set to $N$ and serial number of the station to $i \quad(0<p<N) ; Z$ is the water level. The following steps are performed to solve the model by using the progressive optimality algorithm:

(1) Initialize the algorithm parameters including the search step size and optimal termination precision.

(2) Determine the initial track. The selection of the initial track is crucial in solving the multi-stage and multi-constraint optimization problems by using the progressive optimality algorithm. A proper initial track can accelerate the iterated convergence; otherwise, an improper one easily causes the iteration to converge to the local optimal solution early.

(3) From upstream to downstream, keep the water level $Z_{p, 0}$ and $Z_{p, 2}$ of station $p$ unchanged at No. 0 and No. 2 intervals and adjust the water levels at No. 1 interval $Z_{p, 1}$ (the original level minus one step, original level, and original level plus one step are selected). Thus, there are $3^{\mathrm{N}}$ water level change schemes for cascade hydropower stations, among which $\mathrm{N}$ refers to the number of cascade hydropower stations. When calculating the generating capacity of cascade hydropower stations at No. 0 and No. 1 intervals in each scheme, select one with the largest generating capacity as the new water level at No. 1 interval for each cascade hydropower station.

(4) Similarly, search for the optimal solution for cascade reservoirs at the next interval. Keep the water level $Z_{p, 1}$ and $Z_{p, 3}$ unchanged at No. 1 and No. 3 intervals and adjust water level $Z_{p, 2}$ at No. 2 interval, to maximize the generating capacity of cascade hydropower stations at No. 1 and No. 2 intervals. Then, the water level $Z_{p, 2}$ at No. 2 interval of each hydropower station can be obtained through optimal calculation.

(5) Repeat step (4) until traversing all intervals to complete a circulation, thus obtaining the water level at the end of each calculating interval of all cascade hydropower stations.

(6) Check whether the termination conditions are satisfied. If not, regard the obtained the hydrograph of the cascade hydropower station as the initial track of the next calculation and return to step (3); otherwise, exit from the circulation. The new water level obtained from the last circulation is the optimal storage and discharge policy for cascade hydropower stations.

In practice, the termination conditions can be set as required. The common ones are to give the largest number of iterations, error precision, and change range of the extreme value, among which giving the change range of the extreme value is the most common. By using this method, the change range of the extreme value can be checked when the number of iterations is given. In case of little or no change, the algorithm is terminated. In this paper, the preceding method is used.

\section{Practical Calculation and Result Analysis}

\subsection{River Basin Introduction}

As the largest tributary of the Min River, the Dadu River originates from the southeast foothill of the Golog Mountain in Qinghai province. It has two headwaters, the Markog River in the east and Dokog River in the west. The two headwaters flow together to form the main stem of the Dadu River, Dajin Chuan that meets the Xiaojin 
Chuan together become the Dadu River in name. The main stem has a total length of $1062 \mathrm{~km}, 82700 \mathrm{~km}^{2}$ basin area, and 48.8 billion $\mathrm{m}^{3}$ annual runoff. The basin of the Dadu River shows an "L" type roughly, narrow and long, with the terrain high in the southwest and low in the southeast.

As planned, a total of 28 cascade dams are constructed in the hydropower development of the main stem of the Dadu River, with a total installed capacity of 27 million KW and annual generating capacity of 112.7 billion KWh. The 28 cascade dams are listed as follows: Xiaerxia Dam, Dawei Dam, Busigou Dam, Bala Dam, Shuangjiangkou Dam, Jinchuan Dam, Anning Dam, Badi Dam, Danba Dam, Houziyan Dam, Changheba Dam, Huangjinping Dam, Luding Dam, Yingliangbao Dam, Dagangshan Dam, Longtoushi Dam, Laoyingyan I Dam, Laoyingyan II Dam, Pubugou Dam, Shenxigou Dam, Zhentouba I Dam, Zhentouba II Dam, Shaping I Dam, Shaping II Dam, Gongzui Dam, Tongjiezi Dam, Shawan Dam, and Angu Dam.

\subsection{Basic Parameters of Cascade Reservoirs}

In consideration of the development and construction of cascade reservoirs on the Dadu River, the Pubugou Reservoir, Shenxigou Reservoir and Zhentouba I Reservoir are selected in this paper for analysis in solving the cooperative emergency regulation model for cascading reservoirs in cope with floods exceeding the designed level. Table 1 lists the characteristic water level, characteristic storage, and main dynamic parameters of the three cascading reservoirs in the lower reach of the Dadu River.

Table 1 Main characteristic parameters of three cascading reservoirs in the lower reach of the Dadu River

\begin{tabular}{l|l|l|l}
\hline Name & Pubugou & Shenxigou & Zhentouba \\
\hline Dead Water Level & 790 & 655 & 618 \\
Normal Storage & 850 & 660 & 624 \\
Designed Flood & 848.31 & 652.04 & 618 \\
Checked Flood & 853.78 & 658.38 & 624.45 \\
Dead Storage & 11.8 & 0.244 & 0.29 \\
Regulated & 38.94 & 0.0814 & 0.123 \\
Storage Below & 50.11 & 0.3568 & 0.414 \\
Total Installed & 3600 & 660 & 720 \\
Comprehensive & 8.29 & 8.38 & 8.34 \\
Discharge for & 2722 & 2619 & 2697 \\
\hline
\end{tabular}

Besides the preceding materials, the basic hydrological data needs to be obtained in calculation, such as the curve of the relation between the water level and storage capacity and that of the relation between the water level and the flow in the lower reach. In addition, the information about the flood control design of cascade reservoirs needs to be known. To be specific, the Pubugou Dam is designed to survive 500-year-return floods with the flood discharge of $9460 \mathrm{~m} 3 / \mathrm{s}$; both the Shenxigou Dam and Zhentouba I Dam are designed to prevent 100-year-return floods with the flood discharge of $9400 \mathrm{~m} 3 / \mathrm{s}$. As no flood exceeding the designed level has occurred so far, there is no related data measured about floods exceeding the designed level. Therefore, according to the eigenvalue of the flood with the frequency of $0.1 \%$ in the design flood table for the Pubugou Reservoir and section between the Pubugou Reservoir and Zhentouba Reservoir, the process of flood No. 20150706 to flow into the Pubugou Reservoir and from the Pubugou Reservoir to the Zhentouba I Reservoir with the frequency of $0.1 \%$ is studied in this paper. In particular, the information about floods flowing from the Pubugou Reservoir to Shenxigou Reservoir and from Shenxigou Reservoir to Zhentouba Reservoir is obtained based on the basin area ratio of the two sections.

\subsection{Boundary Condition Setting}

As required by the Flood Control Planning of the Yangtze River, the Pubugou Reservoir shall reserve flood control storage to cooperatively undertake the flood control regulation task in the middle and lower reaches of the Yangtze River. To be specific, the flood control storage of the Pubugou Reservoir is 1.1 billion $\mathrm{m}^{3}$ and its flood control level is $836.2 \mathrm{~m}$ in July. During flood control regulation, the output load of each cascade hydropower station is determined by the power grid. In this paper, in consideration of full use of water resources in flood seasons and full-load output of the generator, the power discharge is set to the discharge for the maximum power of the generator. Table 2 lists the boundary conditions for optimization calculation, including the initial water level and end water level.

Table 2 Settings of boundary conditions for each cascade reservoir in the lower reach of the Dadu River

Water level: $\mathrm{m}$, discharge: $\mathrm{m}^{3} / \mathrm{s}$

\begin{tabular}{|c|c|c|c|c|c|}
\hline Reservoir & Initial & End & Normal & Dead & Power \\
\hline Pubugou & 836.2 & 836.2 & 850 & 790 & 2722 \\
\hline Shenxigou & 658 & 658 & 660 & 655 & 2619 \\
\hline Zhentouba & 620 & 620 & 624 & 618 & 2697 \\
\hline
\end{tabular}

\subsection{Calculation Results and Analysis}

Based on the solution to the cooperative emergency regulation model for floods exceeding the designed level, regulation and calculation of the flood process is conducted. In this way, the water level process and outflow process of each cascade reservoir in the lower reach of the Dadu River are obtained, as shown in Figures 2 to 7 . 


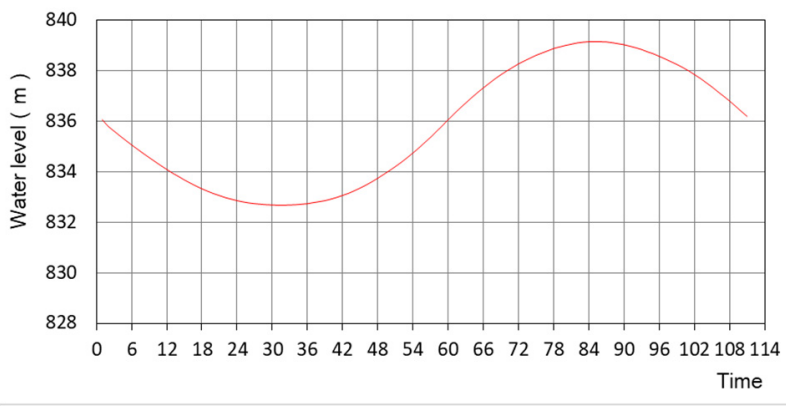

Figure 2 Water level process of the Pubugou Reservoir

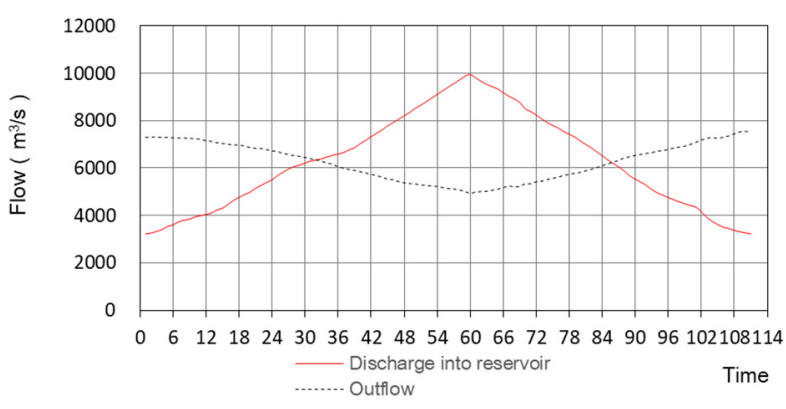

Figure 3 Outflow process of the Pubugou Reservoir

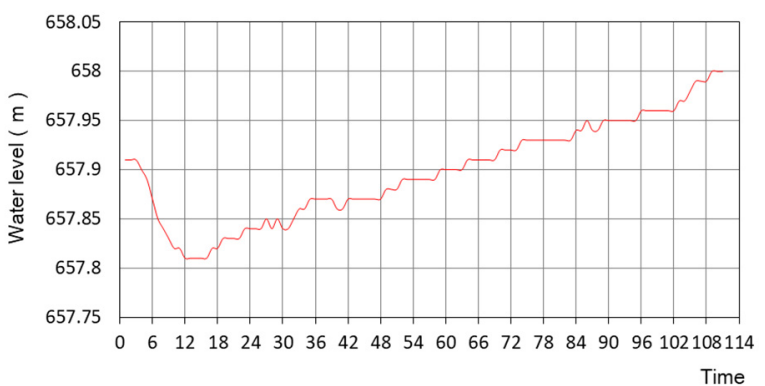

Figure 4 Water level process of the Shenxigou Reservoir

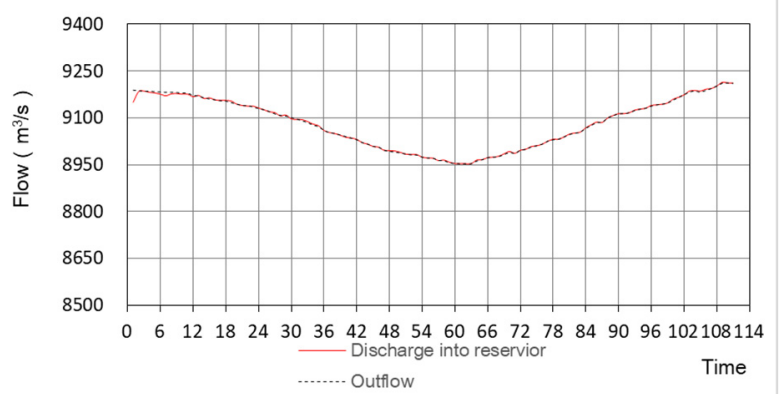

Figure 5 Outflow process of the Shenxigou Reservoir

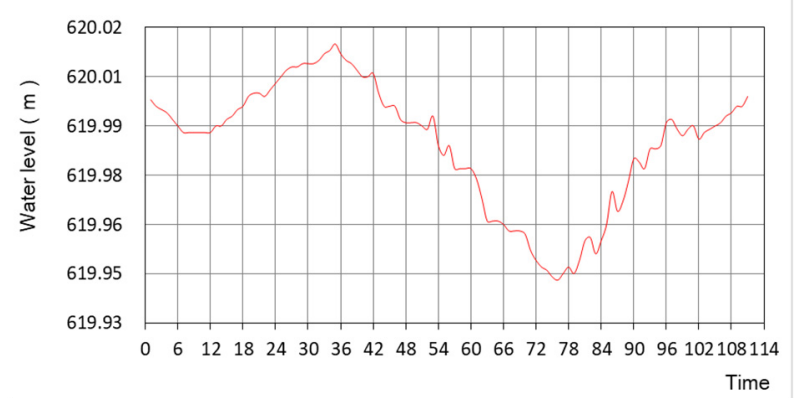

Figure 6 Water level process of the Zhentouba I Reservoir

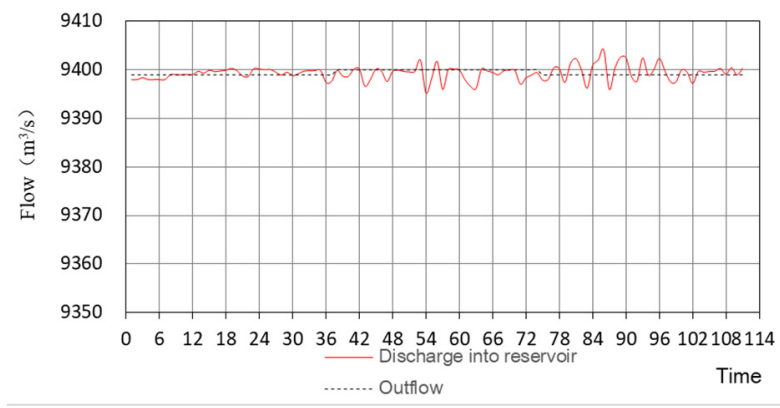

Figure 7 Outflow process of the Zhentouba I Reservoir

According to Figures 2 to 7, by means of cooperative emergency regulation of cascade reservoirs, each reservoir pre-discharges more water in the early flood to maximize the storage capacity, thus coping with the possibly coming flood, minimizing the water level of each reservoir, and effectively securing the flood control for cascade reservoirs. Especially for the leading reservoir with a large flood control storage, such as the Pubugou Reservoir, the preceding results are more obvious.

In conclusion, the cooperative emergency regulation of cascade reservoirs in cope with floods exceeding the designed level can make full use of the regulated storage of cascade reservoirs, effectively mitigate the flood control pressure of cascade reservoirs, and improve the overall flood control capacity of the lower reach of the Dadu River. Therefore, cascade reservoirs in the lower reach of the Dadu River can survive floods exceeding the designed level, well fulfill their flood control tasks, and secure the safe and stable operation of each cascade reservoir, and the safety of the lives and property of people in the surrounding reaches.

\section{Conclusion and Suggestion}

(1) In this paper, the criterion of minimizing the highest water level is chosen as the objective function of the cooperative emergency regulation model in cope with floods exceeding the designed level, with the progressive optimality algorithm adopted to solve the function for cascade reservoirs. Moreover, the related emergency regulation plan is conductively explored, thus significantly improving the emergency response level of cascade reservoirs in cope with floods exceeding the designed level.

(2) The Pubugou Reservoir, Shenxigou Reservoir, and Zhentouba I Reservoir on the Dadu River are taken as examples to regulate and calculate the flooding process, which verified the validity and reliability of the preceding model. The research results are of great reference value for establishing the emergency regulation mechanism to cope with floods exceeding the designed level for cascade reservoirs in each river basin.

(3) In this paper, the progressive optimality algorithm is adopted to solve the emergency regulation model for cascade reservoirs in cope with floods exceeding the designed level. When the calculated amount of the calculation model increases, the solving speed is slow. In 
the future studies, the artificial intelligent algorithm can be introduced to solve the emergency model for cascade reservoirs in cope with floods exceeding the designed level to improve the solution efficiency and precision for the regulation program, provide better guidance for cascade reservoirs to cope with emergent floods exceeding the designed level, and mitigate flood disaster losses.

\section{Acknowledgment}

Fund program: National Key R\&D Program of China (2016YFC0402205-6)

\section{References:}

1. He Xiangyang, Zhou Heqing, Song Yingyu et al. Research and Development of the Emergency Warning and Response System for Reservoirs and Dams [C]. Proceedings of the Annual Meeting of the Chinese Hydraulic Engineering Society, 2016:627-632.

2. Peng Xuehui et al. Studies on Risk Criteria of Reservoirs and Dams in China [M]. China Water \& Power Press, 2015.

3. Li Zhiyuan. Cooperative Regulation and Risk Analysis on Flood Control for Cascade Reservoirs [J]. Jilin Water Resources. 2015(7):39-41.

4. He Xianfeng, Quan Yifeng. Theory and Practice of Dam Operation Risk Assessment [M]. The Yellow River Water Conservancy Press, 2014.

5. Zhang Rui. Risk Analysis and Emergency Response Studies on Dam Overtopping of Cascade Reservoirs [D]. Dalian: Dalian University of Technology, 2016.

6. Zhong Ping'an. Analysis on the Objective Function of Flood Control Optimization and Regulation for Reservoirs [J]. Journal of Economics of Water Resources. 1995(1): 38-44.

7. Guo Shenglian, Chen Jionghong, Liu Pan et al. Progress and Outlook of the Cooperative Optimization and Regulation Studies on Reservoirs [J]. Advances in Water Science, 2010.21(4): 496-503.

8. Xiao Lin. Flood Control Optimization and Regulation Model and Algorithm Research for Reservoirs [D]. North China University of Water Resources and Electric Power, 2008.

9. Zhou Chao, Wang Hongwei, Jiang Xingwen. Emergency Evolutionary Analysis and Reservoir Emergency Response in River Basins [J]. Water Resources and Power, 2014(10): 43-47+25.

10. Jia Benyou, Zhong Ping'an, Chen Juan et al. Cooperative Optimization and Regulation Model of the Complex Flood Control System [J]. Advances in Water Science, 2015 (4): 560-571.

11. Zhong Ping'an. Key Technology Research and Application of Real-time Flood Control Regulation in River Basins [D]. Hohai University, 2006.

12. Chen S J. Yan S. Huang W B. et al. A Method for Optimal Floodgate Regulation in Cascade Reservoirs[J]. Proceedings of the Institution of Civil Engineers-Water Management. 2017.170(2): 81-92.

13. Qian Jinglin, Zhang Songda, Xia Menghe. Application of the Progressive Optimality Algorithm in Flood Control Optimization and Regulation for Cascade Reservoirs [J]. China Rural Water and Hydropower, 2014(8): 22-25.

14. Lu Chengxuan, Fang Shisheng. Studies on Reservoir Flood Control Optimization and Regulation Based on the Genetic Algorithm [J]. China Water Transport: Second Half, 2016.16(8): 110-111.

15. Zou Qiang, Wang Xuemin, Li Anqiang et al. Flood Control Optimization and Regulation Research Based on the Parallel Chaos Quantum-behaved Particle Swarm Algorithm [J]. Journal of Hydraulic Engineering. 2016.47(8): 967-976.

16. Wang J L. Huang W B. Ma G W. et al. An Improved Parthenogenetic Algorithm for Multi-objective Economic Dispatch in Cascaded Hydropower Systems[J]. International Journal of Electrical Power \& Energy Systems.2015. 67: 591-597.

17. Ma Guangwen, Liu Jinhuan, Li Jugen. Cooperative Optimization and Regulation of Cascade reservoirs in River Basins [M]. Beijing: China Electric Power Press, 2008. 